OPEN ACCESS

Edited by:

Dimitrios Davalos,

Case Western Reserve University,

United States

Reviewed by:

Patrick J. Drew,

Pennsylvania State University (PSU),

United States

Anil Zechariah,

Western University, Canada Axel Montagne,

University of Southern California,

United States

*Correspondence:

Michèle Desjardins

michele.desjardins@phy.ulaval.ca

Specialty section:

This article was submitted to

Non-Neuronal Cells,

a section of the journal

Frontiers in Cellular Neuroscience

Received: 17 August 2020 Accepted: 04 December 2020

Published: 15 January 2021

Citation:

Carrier M, Guilbert J, Lévesque J-P, Tremblay M-Ė and Desjardins M (2021) Structural and Functional Features of Developing Brain Capillaries, and Their Alteration in Schizophrenia. Front. Cell. Neurosci. 14:595002. doi: 10.3389/fncel.2020.595002

\section{Structural and Functional Features of Developing Brain Capillaries, and Their Alteration in Schizophrenia}

\author{
Micaël Carrier ${ }^{1,2}$, Jérémie Guilbert ${ }^{3,4}$, Jean-Philippe Lévesque ${ }^{3,4}$, \\ Marie-Ėve Tremblay ${ }^{1,2,5,6,7}$ and Michèle Desjardins ${ }^{3,4 *}$
}

${ }^{1}$ Axe Neurosciences, Centre de recherche du CHU de Québec - Université Laval, Québec, QC, Canada, ${ }^{2}$ Department of Molecular Medicine, Université Laval, Québec, QC, Canada, ${ }^{3}$ Axe Oncologie, Centre de recherche du CHU de Québec, Université Laval, Québec, QC, Canada, ${ }^{4}$ Department of Physics, Physical Engineering and Optics, Université Laval, Québec, QC, Canada, ${ }^{5}$ Division of Medical Sciences, University of Victoria, Victoria, BC, Canada, ${ }^{6}$ Department of Biochemistry and Molecular Biology, The University of British Columbia, Vancouver, BC, Canada, ${ }^{7}$ Neurology and Neurosurgery Department, McGill University, Montréal, QC, Canada

Schizophrenia affects more than $1 \%$ of the world's population and shows very high heterogeneity in the positive, negative, and cognitive symptoms experienced by patients. The pathogenic mechanisms underlying this neurodevelopmental disorder are largely unknown, although it is proposed to emerge from multiple genetic and environmental risk factors. In this work, we explore the potential alterations in the developing blood vessel network which could contribute to the development of schizophrenia. Specifically, we discuss how the vascular network evolves during early postnatal life and how genetic and environmental risk factors can lead to detrimental changes. Blood vessels, capillaries in particular, constitute a dynamic and complex infrastructure distributing oxygen and nutrients to the brain. During postnatal development, capillaries undergo many structural and anatomical changes in order to form a fully functional, mature vascular network. Advanced technologies like magnetic resonance imaging and near infrared spectroscopy are now enabling to study how the brain vasculature and its supporting features are established in humans from birth until adulthood. Furthermore, the contribution of the different neurovascular unit elements, including pericytes, endothelial cells, astrocytes and microglia, to proper brain function and behavior, can be dissected. This investigation conducted among different brain regions altered in schizophrenia, such as the prefrontal cortex, may provide further evidence that schizophrenia can be considered a neurovascular disorder.

Keywords: schizophrenia, blood vessels, claudin-5, neurovascular unit, neurovascular coupling

\section{INTRODUCTION}

Affecting $1 \%$ of the global population, schizophrenia (SCZ) is a disabling neurodevelopmental disorder that has seen little improvement in treatments over the last decades (Insel, 2010), leaving patients with a low quality of life (Ritsner et al., 2003). SCZ shows very high heterogeneity in the positive (i.e., hallucinations, delusions), negative and cognitive symptoms (i.e., incoherent alogia, affective flattening, anhedonia, learning, memory deficits) experienced by patients, which can be 
linked to dysfunction in different brain regions (Norris and Strickland, 2017; Glausier and Lewis, 2018). Many features of this disorder are being investigated and have been reviewed from different perspectives, such as the role of the immune system (Sekar et al., 2016; Hui et al., 2018), dopamine pathways (Weinstein et al., 2017), psychiatric deficits (Bora and Murray, 2014; Catalano et al., 2018) and sex differences (Bordeleau et al., 2019). Known risk factors include genetic variants (Marshall et al., 2017) and environmental factors (e.g., air pollution, stress, infection) (Huttunen and Niskanen, 1978; Gomes and Grace, 2017; Korpela et al., 2020). Another important aspect to consider for proper understanding of the pathogenesis of SCZ is the characterization of postnatal development of the brain and its vasculature, as proper establishment of the neurovasculature via bidirectional communication between endothelial cells (ECs) and central nervous system (CNS) cells (Segarra et al., 2018) is crucial for CNS development.

As the highway of the brain, the neurovasculature serves many roles for brain support by providing ions, oxygen, nutrients, and energy metabolites, while also allowing for communication between the periphery and the brain (McConnell et al., 2017). In homeostatic conditions, cerebral blood flow is regulated by the vasculature based on brain activity, increasing and reducing the flow in regions of high or low need (Peterson et al., 2011). To accomplish these functions, cerebral blood vessels need to develop and mature as an efficient network. Vascularization has been shown to be tightly guided by glial cells, such as microglia and astrocytes (Tata et al., 2015). Previous literature shows evidence of vascular impairments contributing to developmental disorders such as autism (Ouellette et al., 2020), and potentially SCZ (Najjar et al., 2017; Kealy et al., 2020). Although the role of these vascular alterations in SCZ is still not clear, one could hypothesize that vascular changes during development affect the establishment of the blood vessel network, leading brain maturation down a path that eventually results in the symptoms experienced by SCZ patients. This review will underline the current view on the vascular hypothesis through discussing normal postnatal development of the neurovascular unit (NVU) in humans and animal models, the establishment of the neurovascular coupling, as well as the misshaping of this development as a potential contributor to SCZ pathogenesis.

\section{DEVELOPMENT OF THE NEUROVASCULAR UNIT}

The NVU is a relatively recent concept (Iadecola, 2017) that refers to the cellular components [e.g., endothelial cells (ECs), pericyte and astrocyte] that contribute to the functional relationship between brain cells and cerebral vasculature (Coelho-Santos and Shih, 2020) with each cell type having their specific molecular signature (Vanlandewijck et al., 2018). This relationship notably allows for neurovascular coupling (NVC) between neuronal activity and blood flow and the establishment of a properly selective blood-brain barrier $(\mathrm{BBB})$ required to protect the brain against homeostatic disturbance from the periphery (Bell et al., 2019; Sweeney et al., 2019).

\section{Neurovascular Coupling During Normal Development}

Although still an area of active research, the various cellular elements of the BBB play a role in coupling neuronal activity to vascular tone and cerebral blood flow. Astrocytes can react to glutamatergic synaptic signaling by producing vasoactive compounds that cause pericytes to dilate capillaries (Hall et al., 2014; Mishra et al., 2016; Kisler et al., 2017). Capillary ECs can also detect potassium ionic currents and subsequently propagate a vasodilatory signal to upstream arterioles (Longden et al., 2017). Various neuronal subtypes directly signal to the vasculature by producing vasodilative or vasoconstrictive molecules (Uhlirova et al., 2016), for example nitric oxide release by glutamatergic neurons was proposed to suppress release of the vasoconstrictor 20-hydroxyeicosatetraenoic acid by astrocytes (Hall et al., 2014). This neurovascular coupling (NVC) explains the relationship between neuronal activity and the tight modulation of local oxygen/glucose concentration (Iadecola, 2017) and can provide an indirect measure of metabolic demand, which is altered in certain disorders including SCZ (Zhu et al., 2017).

NVC is also the basis for hemodynamic based noninvasive imaging of brain activity. When neuronal activity elicits an increase in blood flow in a given brain region, the rate of oxygen delivery exceeds the rate at which it is consumed, leading to a localized increase in oxyhemoglobin concentration concomitant with a decrease in deoxyhemoglobin (HbR) concentration (Buxton, 2013). With hemodynamic based functional imaging techniques, this change in oxygenation can be measured and used as a proxy for neuronal (and glial) activity. Among those techniques, functional magnetic resonance imaging (fMRI) and near infrared spectroscopy (NIRS) are the most commonly used for imaging neurovascular development in infants (Kozberg and Hillman, 2016; Hendrikx et al., 2019). In fMRI, changes in $\mathrm{HbR}$ concentration create the positive (HbR decrease) or negative (HbR increase) blood oxygenation level-dependent (BOLD) signal (Ogawa et al., 1992; Kim and Ogawa, 2012). Optical functional techniques, such as NIRS and its more invasive equivalent used in rodents, intrinsic optical signals (IOS), also measure $\mathrm{HbR}$ as well as oxy- and total hemoglobin concentration changes. Performing MRI in infants is still very challenging because of its sensitivity to motion artifacts (Dean et al., 2014), whereas NIRS offers a portable alternative for measuring functional hemodynamic signals in the cortex at low cost and which can be used in multiple experimental environments, even in schools (Soltanlou et al., 2018; Whiteman et al., 2018).

MRI and NIRS have shown great potential to measure hemodynamic signals longitudinally (Demirci et al., 2008; Yang et al., 2019) with growing literature investigating development as gathered in Table 1. This table compares results from previous studies in which task-evoked hemodynamic responses were measured in healthy young children or rodents using fMRI or NIRS/IOS. 
TABLE 1 | Summary of 20 years of studies investigating hemodynamic responses at several stages of homeostatic cerebrovascular development.

\begin{tabular}{|c|c|c|c|c|c|c|c|c|}
\hline \multicolumn{9}{|c|}{ fMRI studies } \\
\hline References & Species & State & Stimulation & Age & & & & BOLD results \\
\hline \multirow[t]{2}{*}{ Born et al. (2000) } & Human & Asleep/Awake & Visual & 48 weeks & & & & $\uparrow$ \\
\hline & & & & 56 weeks & & & & $\downarrow$ \\
\hline \multirow[t]{2}{*}{ Yamada et al. (2000) } & Human & - & Visual & 0-7 weeks & & & & $\uparrow$ \\
\hline & & & & 8-22 weeks & & & & $\downarrow$ \\
\hline \multirow[t]{2}{*}{ Anderson et al. (2001) } & Human & Awake & Auditory & 40-50 weeks & & & & $\uparrow$ \\
\hline & & & & 50 weeks & & & & $\downarrow$ \\
\hline Sie et al. (2001) & Human & Sedated & Visual & 18 months & & & & $\downarrow$ \\
\hline Born et al. (2002) & Human & Sedated & Visual & 4-71 weeks & & & & $\downarrow$ \\
\hline Erberich et al. (2006) & Human & Sedated & Somatosensory & 28-46 weeks & & & & $\downarrow$ \\
\hline Colonnese et al. (2008) & Rats & Sedated & Somatosensory & P13 to adulthood & & & & $\uparrow$ \\
\hline \multirow[t]{2}{*}{ Heep et al. (2009) } & Human & Sedated & Somatosensory & Preterm infant (26.5 weeks) & & & & $\downarrow$ \\
\hline & & & & Term infant (39 weeks) & & & & $\downarrow$ \\
\hline \multirow[t]{2}{*}{ Arichi et al. $(2010,2012)$} & Human & Sedated & Somatosensory & Preterm & & & & $\uparrow$ \\
\hline & & & & Term & & & & $\uparrow$ \\
\hline \multicolumn{9}{|c|}{ Optical imaging studies } \\
\hline References & Species & State & Stimulation & Age & $\mathrm{HbO}$ & HbR & $\mathrm{HbT}$ & $\begin{array}{l}\text { BOLD } \\
\text { equivalence }\end{array}$ \\
\hline Sakatani et al. (1999) & Human & Awake & Visual & 3 years & - & - & $\uparrow$ & - \\
\hline \multirow[t]{3}{*}{ Hoshi et al. (2000) } & Human & Asleep & Visual & 4-5 days & $\uparrow$ & $\uparrow$ & $\uparrow$ & - \\
\hline & & & & & & None & & \\
\hline & & & & & & $\downarrow$ & & \\
\hline Zaramella et al. (2001) & Human & Awake/Asleep & Auditory & 0-7 weeks & - & - & $\uparrow$ & - \\
\hline Taga et al. (2003) & Human & Awake & Visual & 2-4 months & $\uparrow$ & $\downarrow$ & - & $\uparrow$ \\
\hline Kusaka et al. (2004) & Human & - & Visual & 4-16 weeks & $\downarrow$ & $\uparrow$ & $\uparrow$ & $\downarrow$ \\
\hline Watanabe et al. (2008) & Human & Awake & Visual & 2-4 months & $\uparrow$ & $\downarrow$ & - & $\uparrow$ \\
\hline Karen et al. (2008) & Human & Asleep & Visual & 2-9 days & $\uparrow$ & $\downarrow$ & $\uparrow$ & $\uparrow$ \\
\hline Liao et al. (2010) & Human & Asleep & Visual & 2 days & $\uparrow$ & $\downarrow$ & $\uparrow$ & $\uparrow$ \\
\hline \multirow{2}{*}{ Kozberg et al. (2013) } & \multirow{2}{*}{ Rats } & \multirow{2}{*}{ Anesthetized } & \multirow{2}{*}{ Somatosensory } & P12-P13 & $\uparrow$ & $\downarrow$ & $\uparrow$ & $\uparrow$ \\
\hline & & & & ( $\sim 1$ year human in humans) & $\downarrow$ & $\uparrow$ & $\downarrow$ & $\downarrow$ \\
\hline Sintsov et al. (2017) & Rats & Non-sedated & Somatosensory & $\begin{array}{l}\text { 0-3 months ( } ~ 8 \text { years in } \\
\text { humans) }\end{array}$ & $\uparrow$ & $\downarrow$ & - & $\uparrow$ \\
\hline
\end{tabular}

The up or down arrows indicate an increase or a decrease, respectively, in the value of the measure of blood oxygen level dependent (BOLD) signal, oxyhemoglobin (HbO), deoxyhemoglobin $(\mathrm{HbR})$ and total hemoglobin $(\mathrm{HbT})$ during the activation period in comparison to the resting period. Multiple arrows in the same box signify different responses observed within the group of the study and no change between those two states is identified by "None." Parameters not reported in these studies are identified with a hyphen (-). Equivalence between rat and human ages were estimated based on (Sengupta, 2013).

Overall, these results are difficult to properly interpret. Although it is known that the hemodynamic response is necessary to induce vessel remodeling (Lucitti et al., 2007), the timeline of developmental patterns of the various components of NVC are not all well-defined, making it difficult to know if the varied hemodynamic responses observed are caused by altered neuronal activity in infants or an immature NVU. Second, as was previously noted (Harris et al., 2011), the lack of standardization in imaging parameters and stimulation paradigms adds many confounding variables when looking for consistent trends in results from functional imaging studies. Given the vascular component of SCZ, it can be investigated using techniques reported in Table 1. In our review of the literature on the hemodynamic response in SCZ patients investigated using NIRS (Ikezawa et al., 2009; Takizawa et al., 2009; Fujita et al., 2011; Kinou et al., 2013; Pu et al., 2015, 2016; Noda et al., 2017) and fMRI (Barch et al., 2003; Kircher et al., 2004; Tregellas et al., 2004, 2009; Ford et al., 2005; Dyckman et al., 2011; Mayer et al., 2013, 2016; Hanlon et al., 2016), no studies were found during development, a question that should be addressed to better understand NVC deficits in SCZ. The structure of the NVU is also a growing field for SCZ research (Villabona-Rueda et al., 2019).

\section{Development of the Capillary Network}

During postnatal development, bidirectional communication between brain cells and the nascent vasculature ensures that capillaries grow side-by-side with the maturing neurons and glial cells so that the latter are provided with sufficient energy 
substrates (Paredes et al., 2018). This results in a dense mesh of capillaries matching the metabolic demand of the neurons and glial cells they support (Craigie, 1945; Weber et al., 2008; Lacoste et al., 2014). In rodents, at birth, the capillary bed is sparse, but goes through a rapid expansion in the first few postnatal weeks. Studies examining capillary growth from birth to adolescence in rodents have consistently shown more than a twofold postnatal increase in measures such as vessel density and volume compared to neurons density and branching before the growth stabilizes at postnatal day (P)20 (Keep and Jones, 1990; Wang et al., 1992; Zeller et al., 1996; Harb et al., 2013). A similar increase is seen in postnatal primates, in which relative vascular volume can double between birth and adulthood, reducing the distance between tissue and the vasculature by $32 \%$. This doubling occurs mostly via angiogenesis and partly from the lengthening of existing vessels (Risser et al., 2009). This vascular increase is thought to originate almost solely from the capillary bed, as the network of larger penetrating arterioles and ascending venules is stable throughout postnatal development (Norman and O'Kusky, 1986; Risser et al., 2009). Interestingly, an earlier study in young rats showed that the vascularization of the capillary bed is not a continuous process, but rather occurs in distinct bouts of intense sprouting between P0 and P4, P7 and P8, at P10 and at P14, across the cerebral cortex (Rowan and Maxwell, 1981) but not the cerebellum (Craigie, 1924). The temporal pattern of sprouting was different across cortical layers, but always more intense in the middle layers, peaking within cortical layer 4 at adulthood (Harrison et al., 2002; Blinder et al., 2013).

Angiogenesis in the capillary bed is highly adaptive during early development. In rodents, enhanced sensory stimulation of the whiskers or complex experiences (e.g., vision) in the first postnatal month can increase capillary density in the somatosensory and visual cortices, respectively (Black et al., 1987; Lacoste et al., 2014). On the other hand, both sensory deprivation and hyperstimulation during that period can result in lower capillary density (Lacoste et al., 2014; Whiteus et al., 2014) without measurable changes in neuronal density in the regions analyzed. The pial vasculature for its part does not seem to adapt to sensory stimuli (Adams et al., 2018).

Following an early critical window, the microvasculature becomes less adaptive: for example, Whiteus et al. (2014) showed that the decreases in capillary density observed following chronic hyperstimulation by repetitive sounds, whisker deflection or motor activity in mice neonates (P15) can be restored if the perturbations were stopped after 5 days, but not if they were sustained for 15 days. Chronic hypoxia, which can induce robust angiogenesis in young mice during the second week of life, has also been shown to stop evoking capillary responses in the somatosensory and motor cortices after 3 months of age (Harb et al., 2013).

\section{Development of the Cellular Components of the NVU}

The main components of the NVU (Figure 1), ECs, exert functions such as the active transport of ions and nutrients through the $\mathrm{BBB}$ via membrane transporters whose levels vary during development. Expression of the P-glycoprotein (PGP) efflux transporter, which is hardly detectable at birth, is upregulated throughout the first postnatal month in mice (Daneman et al., 2010). ECs also upregulate the glucose transporter (GLUT) 1 in the second week to reach adult levels by P30 in rats (Harik et al., 1993; Vannucci and Vannucci, 2000).

The second main component of the NVU is astrocytes and their endfeet. In rodents, astrocytes start to be present in the cortex shortly after birth, and their endfeet typically fully ensheath capillaries by P15 (Mathiisen et al., 2010; Gilbert et al., 2019). In parallel, the gliovascular interface undergoes maturation, as protein complexes at the junction between perivascular astrocytic endfeet are assembled between P10 and P15 (Gilbert et al., 2019). The timing of astrocyte appearance in the cortex differs between species. In humans, this begins embryonically (El-Khoury et al., 2006). When astrocytes appear postnatally, the $\mathrm{BBB}$ is already functional meaning that astrocytes are not required for $\mathrm{BBB}$ function but rather seem to have a role in BBB maintenance later in life (Daneman et al., 2010). In addition, microglia were shown to ensheath the basement membrane of capillaries and contribute to the glia limitans, although their roles in the $\mathrm{BBB}$ formation and maintenance remain largely elusive (Bisht et al., 2016; Joost et al., 2019).

In contrast, pericytes coverage of capillaries is already established in neonatal rodents and is vital for BBB establishment, playing a role in proper tight junction orientation (Daneman et al., 2010; Ben-Zvi et al., 2014). Furthermore, during postnatal angiogenesis, pericytes are recruited to induce the formation of new capillaries via platelet-derived growth factor signaling in mice (Lindblom et al., 2003). Pericyte proliferation decreases steadily in mice from birth to P25 in the somatosensory and motor cortex (Harb et al., 2013). Initially, ECs express cluster of differentiation 146 (CD146) in order to upregulate claudin- 5 forming the BBB. Expression of CD146 by pericytes promote their migration toward the ECs which in turn release transforming growth factor beta 1, down-regulating endothelial CD146 to reduce the expression of claudin-5 (Chen et al., 2017). Of the many components required for the development of the NVU, claudin-5, the dominant component of tight junctions forming the $\mathrm{BBB}$, is already expressed in capillary ECs at P0 (Ek et al., 2006; Greene et al., 2019). In mice, its production increases more than threefold by $\mathrm{P} 15$ before stabilizing, indicating continued postnatal maturation of the BBB (Gilbert et al., 2019). Claudin-5 deficiency, resulting in BBB dysfunction, is causal in animal models of stress and depression (Menard et al., 2017; Pearson-Leary et al., 2017). Furthermore, mutation in claudin-5 is also seen in SCZ human patients (Omidinia et al., 2014) with dysfunction linked to change in other tight junction proteins such as ZO-1 and occludin (Maes et al., 2019; Greene et al., 2020).

\section{Cellular, Vascular, and Genetic Dysfunction in SCZ}

SCZ is recognized to be linked to genetic vulnerabilities (Strawbridge et al., 2018; Chen et al., 2019; D’Ambrosio et al., 2019) (also reviewed in Comer et al., 2020a) 


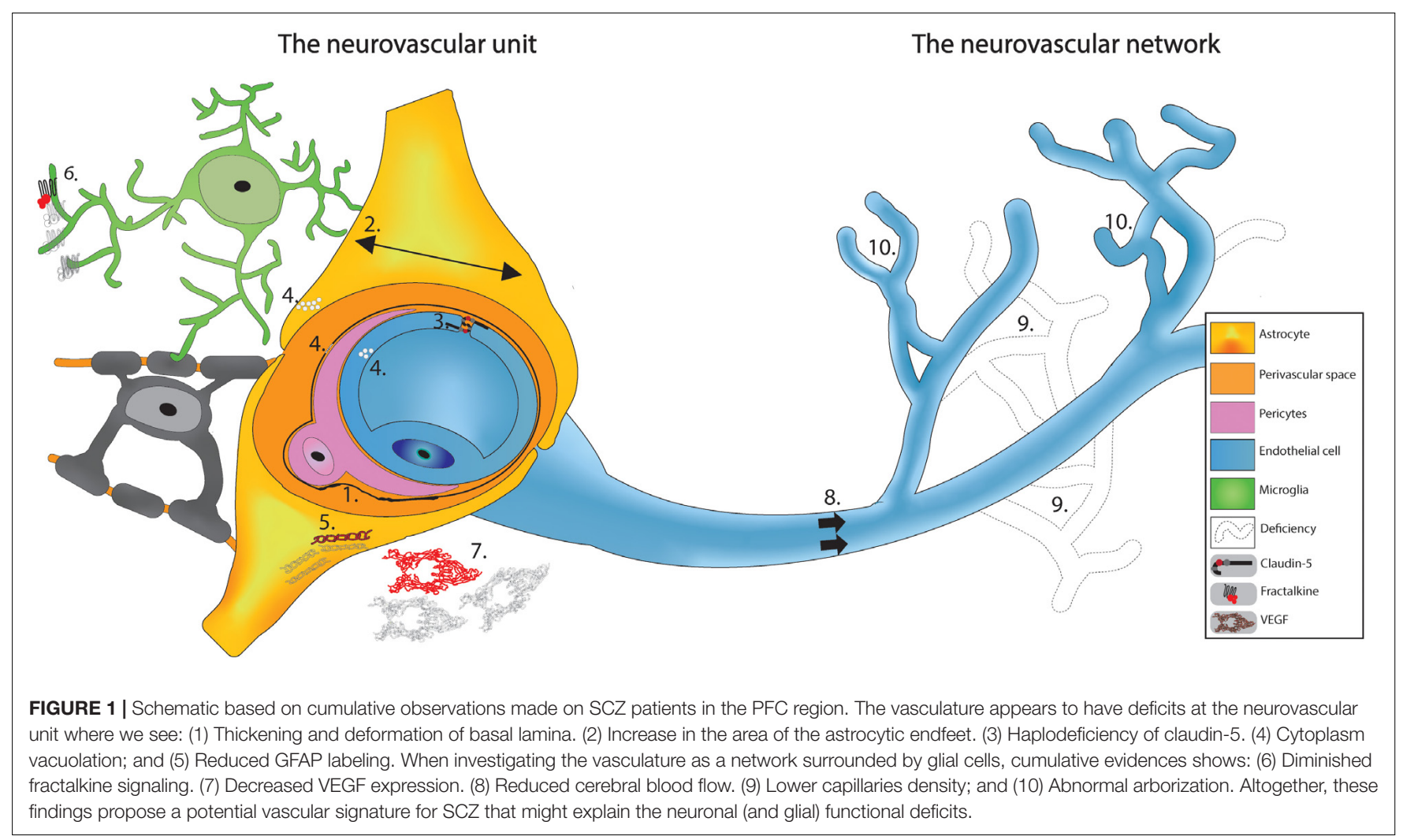

and environmental factors during adolescence and into young adulthood (Pulver, 2000; Gomes and Grace, 2017; Qiu et al., 2019; Barichello et al., 2020). On the vascular level, genetic mutation on the chromosome 22q11 results in the loss of about 40 genes, one gene of interest being claudin-5 (Graw et al., 2012; Tang et al., 2014; Thompson et al., 2017). In mice engineered with a mutation in 22q11, claudin-5 expression is reduced by $75 \%$ in ECs, which was reproduced in cell culture (Greene et al., 2018). Furthermore, using MRI in SCZ patients, the 22q11 mutation was associated with decreased brain volumes for both total grey ( $g=-0.81)$ and total white matter $(g=-0.81)$ calculated by a meta-analysis of between-group differences in mean volumes, representing the effect size ( $g$ ) (Rogdaki et al., 2020). Considering that most investigations on vascular alterations in patients with SCZ are done using post-mortem tissue (McGlashan, 2011; Harris et al., 2012; Katsel et al., 2017), it is difficult to have a good idea on the temporal development of those deficits. To our knowledge, no longitudinal studies have been performed on the vascular aspect of $\mathrm{SCZ}$, a question that remains to be addressed in the field. When the NVU and the BBB are altered in SCZ, then the vasculature would be unable to answer neuronal and glial cells engaging in their normal activities. A post-mortem study showed cardiovascular disorders as the primary cause of death in SCZ patients (Sweeting et al., 2013). More clinical evidence was extensively reviewed by Najjar et al. (2017). Notably, patients show elevation in CSF albumin (higher ratio of CSF-albumin to P-albumin), IgG, IgM, S100B and in several vascular endothelial adhesion molecules (soluble platelet selectin, serum L-selectin, integrin $\alpha$ IIb $\beta$ IIIa, receptors on platelets) as well as decreases in vascular endothelial growth factor (VEGF) (Najjar et al., 2017; Melkersson and Bensing, 2018). In living human studies using dynamic contrast-enhanced (DCE)-MRI to study BBB integrity of the hippocampus, investigations pertaining to dementia and related disorders are extensive (Raja et al., 2018; Nation et al., 2019) but have not yet been targeted at the specific case of SCZ.

\section{Vascular Dysfunction in SCZ PFC}

Brain imaging in SCZ patients investigating the hemodynamic response has been performed using fMRI (Hanlon et al., 2016). Although data is lacking about the prodromal stage, many vascular correlates of the disease have been identified. The PFC has been the subject of a great number of studies detailing the vasculature in SCZ, but is not the only region implicated. Whole brain analysis using inflow-based vascular-space-occupancy MRI also show significant reduction in arterial cerebral brain volume in temporal cortex grey matter of SCZ patients (Hua et al., 2017). Studies using different MRI sequences found reduced CBF in the frontal lobe (Malaspina et al., 2004), temporal lobe (Kindler et al., 2015), parietal lobe (Scheef et al., 2010) and occipital lobe (Pinkham et al., 2011).

SCZ patients also show morphological and functional alteration in glial cells present in this region, such as microglia (Bordeleau et al., 2019) and astrocytes (Abbink et al., 2019). Dark microglia, classified as such by their electron dense cytoplasm, have been found in numerous pathological conditions including in patients with SCZ and animal models of schizophrenialike disorder simulated with the viral mimic poly I:C (Hui et al., 2018; St-Pierre et al., 2020). These altered microglia 
make extensive interactions with the NVU and have been suggested to take over astrocytic functions in SCZ (St-Pierre et al., 2020). Investigations of astrocytes in SCZ patients revealed larger astrocytic endfeet covering vessels (Uranova et al., 2010). This could be a compensation mechanism for the decreased astrocytic density seen in SCZ patients (Najjar et al., 2017), resulting in missing NVU components (Figure 1). There are also myelination deficits in patients with SCZ, implicating another glial cell type, oligodendrocytes (Raabe et al., 2018). A recent review has highlighted the need for NVU integrity to promote oligodendrocyte survival, potentially explaining the myelination deficit in SCZ (Hamanaka et al., 2018).

All three glial cell types appear to be key players in SCZ as covered in reviews focused on the subject (Bernstein et al., 2015). Astrocytes and microglia play key roles in controlling cerebral blood flow in a calcium dependent way as shown in mice (Mulligan and MacVicar, 2004; Mishra et al., 2016; Kleinberger et al., 2017). Overall, defects in the PFC vasculature and alterations in glial cells in SCZ investigations keep emerging, allowing us to both revisit existing and draw new hypotheses on its pathophysiology.

\section{DISCUSSION}

\section{The Vascular Hypothesis}

Although many of the findings discussed above are recent, the vasculature hypothesis of SCZ is not. As highlighted in a brief history (Meier et al., 2013) based on a century old hypothesis (McGlashan, 2011), symptoms of SCZ could possibly be explained by cerebral microvasculature damages (Hanson and Gottesman, 2005). A possible mechanism is systemic inflammation shown in SCZ patients (Cai et al., 2020) coming from environmental factors (e.g., pollution, stress, nutrition induced gut-brain axis dysbiosis, viral infection, maternal immune activation) and genetic predisposition as the source of perturbation (Comer et al., 2020a). This inflammation is detrimental to the development of the vasculature, possibly already weakened by genetic mutation resulting in cellular damage (Hanson and Gottesman, 2005). The affected cells of the NVC would fail to maintain $\mathrm{BBB}$ integrity resulting in leakiness, associated with homeostatic disturbance from the periphery (e.g., inflammatory mediators and cells), and blood flow reduction providing limited oxygen and nutrient supply to the brain, impairing brain maturation. This mechanism is consistent with evidence seen in other disorders such as Alzheimer (Korte et al., 2020) and could explain the higher probability of neurodegenerative disorder in diabetic patients in which many vascular anomalies are observed (Nelson et al., 2016). Alterations in glial cells (mainly microglia and astrocytes) could contribute to this neurovascular fragility (Figure 1). Growing evidence place the PFC as central in this hypothesis because multiple investigations on SCZ patients found vascular defects in this particular region, ranging from decreases in claudin-5 (Greene et al., 2018), reductions in VEGF signaling (Fulzele and Pillai, 2009; Huang et al., 2020), a less dense capillary network (Uranova et al., 2013), to oversimplified angioarchitecture (Senitz and Winkelmann, 1991; Uranova et al., 2010), and other ultrastructural defects (Figure 1; Webster et al., 2001; Uranova et al., 2010; Ishizuka et al., 2017; Hill et al., 2020). As many key components of NVC are impacted by SCZ, it is not surprising that one of the most consistently observed neurovascular correlates of the illness is hypo-activity in PFC regions and in the left superior temporal gyrus, as revealed by a recent systematic review of both task and restingstate fMRI cross-sectional studies in first-episode SCZ patients (Mwansisya et al., 2017).

Although this hypothesis places the vasculature as a central element of SCZ, it is not clear whether the structural and functional abnormalities in blood vessels are a cause or a consequence of the cortical maturation deficiency. Growing evidence shows that an abnormal pruning of synapses and neurons by microglia potentially causes the cortical deficiency associated with SCZ (Sellgren et al., 2019). This altered removal of synapses is still partially unexplained, although it may result from dysfunctional fractalkine, triggering receptor expressed on myeloid cells 2 or complement signaling (Paolicelli et al., 2011; Hoshiko et al., 2012; Schafer et al., 2012; Filipello et al., 2018), all involved in microglia-mediated synaptic pruning. Complement is a prime suspect as work has shown upregulation of complement 4 protein in SCZ patients' brain (Sekar et al., 2016) and mouse models of SCZ (Comer et al., 2020b). When compared to other neurodegenerative disorders, the SCZ vascular hypothesis has similitudes with the recent vascular hypothesis for dementia (Ting et al., 2016), with differences in the affected regions. For example, vascular dementia is considered to arise from vascular defects in the white matter (Dichgans and Leys, 2017; Iadecola, 2017). For SCZ, beyond defects in the PFC represented in Figure 1, recent evidence points in the direction of vascular dysfunction in the brain network responsible for treatment of visual stimuli (Lefebvre et al., 2020), possibly resulting in hallucination.

\section{CONCLUSION}

Projects investigating the immune and vascular components of SCZ in the same protocol are required more than ever to shed light on the pathophysiology of SCZ. This should be approached in more causal studies for the vascular hypothesis to take traction in the SCZ field. A potential avenue would be based on previous work suggesting microvascular damages are coming from hypoxia induced factor 1 after lack of oxygenation during prenatal or early postnatal development (SchmidtKastner et al., 2012). This could mean inducing the conditional production of hypoxia induced factor 1 in a double hit protocol to potentially reproduce SCZ-like behavior, thus providing an effective model to the field. The models could then be investigated using 2-photon microscopy to measure blood velocity and glial interactions with the vasculature (Letourneur et al., 2014). Another way would be to directly induce hypoxia in animal models, as done for other pediatric conditions (Johnson et al., 2018; Kiernan et al., 2019) and see if this can reproduce a similar outcome as seen in SCZ patients. In both models, investigating 
the vascular and the immune dynamic could provide a new understanding leading to novel therapeutic approaches for SCZ.

\section{AUTHOR CONTRIBUTIONS}

MC was responsible for planning and managing the review, writing of the introduction, discussion, and schizophrenia section while taking care of the overall revision and formatting of the manuscript, and is also the creator of the figure included in the manuscript. JG was in charge of writing the neurovascular unit section and contributing to the neurovascular coupling of the manuscript and on the literature search included in the figure creation. J-PL was responsible for writing the neurovascular coupling section and creating the table. MD and M-ÈT were in charge of revising the manuscript and contributed to the theoretical and writing part of the manuscript while MD contributed significantly to the organization and design of the manuscript. All authors contributed to the article and approved the submitted version.

\section{REFERENCES}

Abbink, M. R., van Deijk, A. F., Heine, V. M., Verheijen, M. H., and Korosi, A. (2019). The involvement of astrocytes in early-life adversity induced programming of the brain. Glia 67, 1637-1653. doi: 10.1002/glia.23625

Adams, M. D., Winder, A. T., Blinder, P., and Drew, P. J. (2018). The pial vasculature of the mouse develops according to a sensory-independent program. Sci. Rep. 8:9860. doi: 10.1038/s41598-018-27910-3

Anderson, A. W., Marois, R., Colson, E. R., Peterson, B. S., Duncan, C. C., Ehrenkranz, R. A., et al. (2001). Neonatal auditory activation detected by functional magnetic resonance imaging. Magn. Reson. Imaging 19, 1-5. doi: 10.1016/s0730-725x(00)00231-9

Arichi, T., Fagiolo, G., Varela, M., Melendez-Calderon, A., Allievi, A., Merchant, N., et al. (2012). Development of BOLD signal hemodynamic responses in the human brain. NeuroImage 63, 663-673. doi: 10.1016/j.neuroimage.2012.06.054

Arichi, T., Moraux, A., Melendez, A., Doria, V., Groppo, M., Merchant, N., et al. (2010). Somatosensory cortical activation identified by functional MRI in preterm and term infants. NeuroImage 49, 2063-2071. doi: 10.1016/j. neuroimage.2009.10.038

Barch, D. M., Mathews, J. R., Buckner, R. L., Maccotta, L., Csernansky, J. G., and Snyder, A. Z. (2003). Hemodynamic responses in visual, motor, and somatosensory cortices in schizophrenia. Neuroimage 20, 1884-1893. doi: 10. 1016/s1053-8119(03)00449-x

Barichello, T., Simoes, L. R., Quevedo, J., and Zhang, X. Y. (2020). Microglial activation and psychotic disorders: evidence from pre-clinical and clinical studies. Curr. Top. Behav. Neurosci. 44, 161-205. doi: 10.1007/7854_2018_81

Bell, A. H., Miller, S. L., Castillo-Melendez, M., and Malhotra, A. (2019). The neurovascular unit: effects of brain insults during the perinatal period. Front. Neurosci. 13:1452. doi: 10.3389/fnins.2019.01452

Ben-Zvi, A., Lacoste, B., Kur, E., Andreone, B. J., Mayshar, Y., Yan, H., et al. (2014). Mfsd2a is critical for the formation and function of the blood-brain barrier. Nature 509, 507-511. doi: 10.1038/nature13324

Bernstein, H.-G., Steiner, J., Guest, P. C., Dobrowolny, H., and Bogerts, B. (2015). Glial cells as key players in schizophrenia pathology: recent insights and concepts of therapy. Schizophr. Res. 161, 4-18. doi: 10.1016/j.schres.2014.03. 035

Bisht, K., Sharma, K. P., Lecours, C., Gabriela Sánchez, M., El Hajj, H., Milior, G., et al. (2016). Dark microglia: a new phenotype predominantly associated with pathological states. Glia 64, 826-839. doi: 10.1002/glia. 22966

\section{FUNDING}

This work was supported by grants from the Natural Sciences and Engineering Research Council of Canada (NSERC) and the Fonds de recherche du Québec-Nature et technologies (FRQNT), to MD. MC was supported by a Master training award from the Fonds de recherche du Québec-Santé (FRQS). JG was supported by a NSERC training grant. J-PL was supported by a training grant from the Ministère de la Santé et des Services sociaux du Québec. M-ÈT holds a Canada Research Chair (Tier 2) in Neurobiology of Aging and Cognition.

\section{ACKNOWLEDGMENTS}

We are grateful to our colleagues for sharing their insights and contributing to our manuscript through their expertise and time, especially Haley Vecchiarelli for her revision and proofing of the text.

Black, J. E., Sirevaag, A. M., and Greenough, W. T. (1987). Complex experience promotes capillary formation in young rat visual cortex. Neurosci. Lett. 83, 351-355. doi: 10.1016/0304-3940(87)90113-3

Blinder, P., Tsai, P. S., Kaufhold, J. P., Knutsen, P. M., Suhl, H., and Kleinfeld, D. (2013). The cortical angiome: an interconnected vascular network with noncolumnar patterns of blood flow. Nat. Neurosci. 16, 889-897. doi: 10.1038/ nn. 3426

Bora, E., and Murray, R. M. (2014). Meta-analysis of cognitive deficits in ultrahigh risk to psychosis and first-episode psychosis: do the cognitive deficits progress over, or after, the onset of psychosis? Schizophr. Bull. 40, 744-755. doi: $10.1093 /$ schbul/sbt085

Bordeleau, M., Carrier, M., Luheshi, G. N., and Tremblay, M. -È. (2019). Microglia along sex lines: from brain colonization, maturation and function, to implication in neurodevelopmental disorders. Semin. Cell Dev. Biol. 94, 152-163. doi: 10.1016/j.semcdb.2019.06.001

Born, A. P., Miranda, M. J., Rostrup, E., Toft, P. B., Peitersen, B., Larsson, H. B., et al. (2000). Functional magnetic resonance imaging of the normal and abnormal visual system in early life. Neuropediatrics 31, 24-32. doi: 10.1055/ s-2000- 15402

Born, A. P., Rostrup, E., Miranda, M. J., Larsson, H. B. W., and Lou, H. C. (2002). Visual cortex reactivity in sedated children examined with perfusion MRI (FAIR). Magn. Reson. Imaging 20, 199-205. doi: 10.1016/s0730-725x(02) 00469- 1

Buxton, R. B. (2013). The physics of functional magnetic resonance imaging (fMrI). Rep. Prog. Phys. Phys. Soc. G. B. 76:096601. doi: 10.1088/0034-4885/ 76/9/096601

Cai, H. Q., Catts, V. S., Webster, M. J., Galletly, C., Liu, D., O’Donnell, M., et al. (2020). Increased macrophages and changed brain endothelial cell gene expression in the frontal cortex of people with schizophrenia displaying inflammation. Mol. Psychiatry 25, 761-775. doi: 10.1038/s41380-018-0235-x

Catalano, L. T., Heerey, E. A., and Gold, J. M. (2018). The valuation of social rewards in schizophrenia. J. Abnorm. Psychol. 127, 602-611. doi: 10.1037/ abn0000366

Chen, J., Calhoun, V. D., Lin, D., Perrone-Bizzozero, N. I., Bustillo, J. R., Pearlson, G. D., et al. (2019). shared genetic risk of schizophrenia and gray matter reduction in 6p22.1. Schizophr. Bull. 45, 222-232. doi: 10.1093/schbul/sby010

Chen, J., Luo, Y., Hui, H., Cai, T., Huang, H., Yang, F., et al. (2017). CD146 coordinates brain endothelial cell-pericyte communication for blood-brain barrier development. Proc. Natl. Acad. Sci. U.S.A. 114, E7622-E7631. doi: 10. 1073/pnas.1710848114 
Coelho-Santos, V., and Shih, A. Y. (2020). Postnatal development of cerebrovascular structure and the neurogliovascular unit. Wiley Interdiscip. Rev. Dev. Biol. 9:e363. doi: 10.1002/wdev.363

Colonnese, M. T., Phillips, M. A., Constantine-Paton, M., Kaila, K., and Jasanoff, A. (2008). Development of hemodynamic responses and functional connectivity in rat somatosensory cortex. Nat. Neurosci. 11, 72-79. doi: 10.1038/nn2017

Comer, A. L., Carrier, M., Tremblay, M. -È, and Cruz-Martín, A. (2020a). The inflamed brain in schizophrenia: the convergence of genetic and environmental risk factors that lead to uncontrolled neuroinflammation. Front. Cell. Neurosci. 14:274. doi: 10.3389/fncel.2020.00274

Comer, A. L., Jinadasa, T., Sriram, B., Phadke, R. A., Kretsge, L. N., Nguyen, T. P. H., et al. (2020b). Increased expression of schizophrenia-associated gene C4 leads to hypoconnectivity of prefrontal cortex and reduced social interaction. PLoS Biol. 18:e3000604. doi: 10.1371/journal.pbio.3000604

Craigie, E. H. (1924). Changes in vascularity in the brain stem and cerebellum of the albino rat between birth and maturity. J. Comp. Neurol. 38, 27-48. doi: 10.1002/cne.900380103

Craigie, E. H. (1945). The architecture of the cerebral capillary bed. Biol. Rev. Camb. Philos. Soc. 20, 133-146. doi: 10.1111/j.1469-185x.1945.tb00446.x

D’Ambrosio, E., Dahoun, T., Pardiñas, A. F., Veronese, M., Bloomfield, M. A. P., Jauhar, S., et al. (2019). The effect of a genetic variant at the schizophrenia associated AS3MT/BORCS7 locus on striatal dopamine function: a PET imaging study. Psychiatry Res. Neuroimaging 291, 34-41. doi: 10.1016/j. pscychresns.2019.07.005

Daneman, R., Zhou, L., Kebede, A. A., and Barres, B. A. (2010). Pericytes are required for blood-brain barrier integrity during embryogenesis. Nature 468, 562-566. doi: 10.1038/nature09513

Dean, D. C., Dirks, H., O’Muircheartaigh, J., Walker, L., Jerskey, B. A., Lehman, K., et al. (2014). Pediatric neuroimaging using magnetic resonance imaging during non-sedated sleep. Pediatr. Radiol. 44, 64-72. doi: 10.1007/s00247-013-2752-8

Demirci, O., Clark, V. P., Magnotta, V. A., Andreasen, N. C., Lauriello, J., Kiehl, K. A., et al. (2008). A review of challenges in the use of fMRI for disease classification / characterization and a projection pursuit application from multisite fMRI schizophrenia study. Brain Imaging Behav. 2, 147-226. doi: 10.1007/ s11682-008-9028-1

Dichgans, M., and Leys, D. (2017). Vascular cognitive impairment. Circ. Res. 120, 573-591. doi: 10.1161/CIRCRESAHA.116.308426

Dyckman, K. A., Lee, A. K. C., Agam, Y., Vangel, M., Goff, D. C., Barton, J. J. S., et al. (2011). Abnormally persistent fMRI activation during antisaccades in schizophrenia: a neural correlate of perseveration? Schizophr. Res. 132, 62-68. doi: 10.1016/j.schres.2011.07.026

Ek, C. J., Dziegielewska, K. M., Stolp, H., and Saunders, N. R. (2006). Functional effectiveness of the blood-brain barrier to small water-soluble molecules in developing and adult opossum (Monodelphis domestica). J. Comp. Neurol. 496, 13-26. doi: 10.1002/cne.20885

El-Khoury, N., Braun, A., Hu, F., Pandey, M., Nedergaard, M., Lagamma, E. F., et al. (2006). Astrocyte end-feet in germinal matrix, cerebral cortex, and white matter in developing infants. Pediatr. Res. 59, 673-679. doi: 10.1203/01.pdr. 0000214975.85311.9c

Erberich, S. G., Panigrahy, A., Friedlich, P., Seri, I., Nelson, M. D., and Gilles, F. (2006). Somatosensory lateralization in the newborn brain. NeuroImage 29, 155-161. doi: 10.1016/j.neuroimage.2005.07.024

Filipello, F., Morini, R., Corradini, I., Zerbi, V., Canzi, A., Michalski, B., et al. (2018). The microglial innate immune receptor TREM2 is required for synapse elimination and normal brain connectivity. Immunity 48, 979-991.e8. doi: 10 . 1016/j.immuni.2018.04.016

Ford, J. M., Johnson, M. B., Whitfield, S. L., Faustman, W. O., and Mathalon, D. H. (2005). Delayed hemodynamic responses in schizophrenia. Neuroimage 26, 922-931. doi: 10.1016/j.neuroimage.2005.03.001

Fujita, Y., Takebayashi, M., Hisaoka, K., Tsuchioka, M., Morinobu, S., and Yamawaki, S. (2011). Asymmetric alternation of the hemodynamic response at the prefrontal cortex in patients with schizophrenia during electroconvulsive therapy: a near-infrared spectroscopy study. Brain Res. 1410, 132-140. doi: 10.1016/j.brainres.2011.06.052

Fulzele, S., and Pillai, A. (2009). Decreased VEGF mRNA expression in the dorsolateral prefrontal cortex of schizophrenia subjects. Schizophr. Res. 115, 372-373. doi: 10.1016/j.schres.2009.06.005
Gilbert, A., Vidal, X. E., Estevez, R., Cohen-Salmon, M., and Boulay, A.-C. (2019). Postnatal development of the astrocyte perivascular MLC1/GlialCAM complex defines a temporal window for the gliovascular unit maturation. Brain Struct. Funct. 224, 1267-1278. doi: 10.1007/s00429-019-01832-w

Glausier, J. R., and Lewis, D. A. (2018). Mapping pathologic circuitry in schizophrenia. Handb. Clin. Neurol. 150, 389-417. doi: 10.1016/B978-0-44463639-3.00025-6

Gomes, F. V., and Grace, A. A. (2017). Adolescent stress as a driving factor for schizophrenia development-a basic science perspective. Schizophr. Bull. 43, 486-489. doi: 10.1093/schbul/sbx033

Graw, S. L., Swisshelm, K., Floyd, K., Carstens, B. J., Wamboldt, M. Z., Ross, R. G., et al. (2012). Isochromosome 13 in a patient with childhood-onset schizophrenia, ADHD, and motor tic disorder. Mol. Cytogenet. 5:2. doi: 10. 1186/1755-8166-5-2

Greene, C., Hanley, N., and Campbell, M. (2019). Claudin-5: gatekeeper of neurological function. Fluids Barriers CNS 16:3. doi: 10.1186/s12987-0190123-z

Greene, C., Hanley, N., and Campbell, M. (2020). Blood-brain barrier associated tight junction disruption is a hallmark feature of major psychiatric disorders. Transl. Psychiatry 10:373. doi: 10.1038/s41398-020-01054-3

Greene, C., Kealy, J., Humphries, M. M., Gong, Y., Hou, J., Hudson, N., et al. (2018). Dose-dependent expression of claudin-5 is a modifying factor in schizophrenia. Mol. Psychiatry 23, 2156-2166. doi: 10.1038/mp.2017.156

Hall, C. N., Reynell, C., Gesslein, B., Hamilton, N. B., Mishra, A., Sutherland, B. A., et al. (2014). Capillary pericytes regulate cerebral blood flow in health and disease. Nature 508, 55-60. doi: 10.1038/nature13165

Hamanaka, G., Ohtomo, R., Takase, H., Lok, J., and Arai, K. (2018). White-matter repair: interaction between oligodendrocytes and the neurovascular unit. Brain Circ. 4, 118-123. doi: 10.4103/bc.bc_15_18

Hanlon, F. M., Shaff, N. A., Dodd, A. B., Ling, J. M., Bustillo, J. R., Abbott, C. C., et al. (2016). Hemodynamic response function abnormalities in schizophrenia during a multisensory detection task. Hum. Brain Mapp. 37, 745-755. doi: 10.1002/hbm. 23063

Hanson, D. R., and Gottesman, I. I. (2005). Theories of schizophrenia: a geneticinflammatory-vascular synthesis. BMC Med. Genet. 6:7. doi: 10.1186/14712350-6-7

Harb, R., Whiteus, C., Freitas, C., and Grutzendler, J. (2013). In vivo imaging of cerebral microvascular plasticity from birth to death. J. Cereb. Blood Flow Metab. Off. J. Int. Soc. Cereb. Blood Flow Metab. 33, 146-156. doi: 10.1038/jcbfm. 2012.152

Harik, S. I., Hall, A. K., Richey, P., Andersson, L., Lundahl, P., and Perry, G. (1993). Ontogeny of the erythroid/HepG2-type glucose transporter (GLUT-1) in the rat nervous system. Brain Res. Dev. Brain Res. 72, 41-49. doi: 10.1016/01653806(93)90157-6

Harris, J. J., Reynell, C., and Attwell, D. (2011). The physiology of developmental changes in BOLD functional imaging signals. Dev. Cogn. Neurosci. 1, 199-216. doi: 10.1016/j.den.2011.04.001

Harris, L. W., Pietsch, S., Cheng, T. M. K., Schwarz, E., Guest, P. C., and Bahn, S. (2012). Comparison of peripheral and central schizophrenia biomarker profiles. PLoS One 7:e46368. doi: 10.1371/journal.pone.0046368

Harrison, R. V., Harel, N., Panesar, J., and Mount, R. J. (2002). Blood capillary distribution correlates with hemodynamic-based functional imaging in cerebral cortex. Cereb. Cortex N. Y. N 1991, 225-233. doi: 10.1093/cercor/12. 3.225

Heep, A., Scheef, L., Jankowski, J., Born, M., Zimmermann, N., Sival, D., et al. (2009). Functional magnetic resonance imaging of the sensorimotor system in preterm infants. Pediatrics 123, 294-300. doi: 10.1542/peds.2007-3475

Hendrikx, D., Smits, A., Lavanga, M., De Wel, O., Thewissen, L., Jansen, K., et al. (2019). Measurement of neurovascular coupling in neonates. Front. Physiol. 10:65. doi: 10.3389/fphys.2019.00065

Hill, S. L., Shao, L., and Beasley, C. L. (2020). Diminished levels of the chemokine fractalkine in post-mortem prefrontal cortex in schizophrenia but not bipolar disorder. World J. Biol. Psychiatry Off. J. World Fed. Soc. Biol. Psychiatry 1-10. doi: 10.1080/15622975.2020.1755451 [Epub ahead of print].

Hoshi, Y., Oda, I., Wada, Y., Ito, Y., Yamashita, Y., Oda, M., et al. (2000). Visuospatial imagery is a fruitful strategy for the digit span backward task: a 
study with near-infrared optical tomography. Brain Res. Cogn. Brain Res. 9, 339-342. doi: 10.1016/s0926-6410(00)00006-9

Hoshiko, M., Arnoux, I., Avignone, E., Yamamoto, N., and Audinat, E. (2012). Deficiency of the microglial receptor CX3CR1 impairs postnatal functional development of thalamocortical synapses in the barrel cortex. J. Neurosci. Off. J. Soc. Neurosci. 32, 15106-15111. doi: 10.1523/JNEUROSCI.1167-12.2012

Hua, J., Brandt, A. S., Lee, S., Blair, N. I. S., Wu, Y., Lui, S., et al. (2017). Abnormal grey matter arteriolar cerebral blood volume in schizophrenia measured with 3D inflow-based vascular-space-occupancy MRI at 7T. Schizophr. Bull. 43, 620-632. doi: 10.1093/schbul/sbw109

Huang, G., Osorio, D., Guan, J., Ji, G., and Cai, J. J. (2020). Overdispersed gene expression in schizophrenia. NPJ Schizophr. 6:9. doi: 10.1038/s41537-020-00975

Hui, C. W., St-Pierre, A., El Hajj, H., Remy, Y., Hébert, S. S., Luheshi, G. N., et al. (2018). Prenatal immune challenge in mice leads to partly sexdependent behavioral, microglial, and molecular abnormalities associated with schizophrenia. Front. Mol. Neurosci. 11:13. doi: 10.3389/fnmol.2018.00013

Huttunen, M. O., and Niskanen, P. (1978). Prenatal loss of father and psychiatric disorders. Arch. Gen. Psychiatry 35, 429-431. doi: 10.1001/archpsyc.1978. 01770280039004

Iadecola, C. (2017). The neurovascular unit coming of age: a journey through neurovascular coupling in health and disease. Neuron 96, 17-42. doi: 10.1016/j. neuron.2017.07.030

Ikezawa, K., Iwase, M., Ishii, R., Azechi, M., Canuet, L., Ohi, K., et al. (2009). Impaired regional hemodynamic response in schizophrenia during multiple prefrontal activation tasks: a two-channel near-infrared spectroscopy study. Schizophr. Res. 108, 93-103. doi: 10.1016/j.schres.2008.12.010

Insel, T. R. (2010). Rethinking schizophrenia. Nature 468, 187-193. doi: 10.1038/ nature 09552

Ishizuka, K., Fujita, Y., Kawabata, T., Kimura, H., Iwayama, Y., Inada, T., et al. (2017). Rare genetic variants in CX3CR1 and their contribution to the increased risk of schizophrenia and autism spectrum disorders. Transl. Psychiatry 7:e1184. doi: $10.1038 /$ tp. 2017.173

Johnson, S. M., Randhawa, K. S., Epstein, J. J., Gustafson, E., Hocker, A. D., Huxtable, A. G., et al. (2018). Gestational intermittent hypoxia increases susceptibility to neuroinflammation and alters respiratory motor control in neonatal rats. Respir. Physiol. Neurobiol. 256, 128-142. doi: 10.1016/j.resp.2017. 11.007

Joost, E., Jordão, M. J. C., Mages, B., Prinz, M., Bechmann, I., and Krueger, M. (2019). Microglia contribute to the glia limitans around arteries, capillaries and veins under physiological conditions, in a model of neuroinflammation and in human brain tissue. Brain Struct. Funct. 224, 1301-1314. doi: 10.1007/s00429019-01834-8

Karen, T., Morren, G., Haensse, D., Bauschatz, A. S., Bucher, H. U., and Wolf, M. (2008). Hemodynamic response to visual stimulation in newborn infants using functional near-infrared spectroscopy. Hum. Brain Mapp. 29, 453-460. doi: $10.1002 / \mathrm{hbm} .20411$

Katsel, P., Roussos, P., Pletnikov, M., and Haroutunian, V. (2017). Microvascular anomaly conditions in psychiatric disease. Schizophrenia - angiogenesis connection. Neurosci. Biobehav. Rev. 77, 327-339. doi: 10.1016/j.neubiorev. 2017.04.003

Kealy, J., Greene, C., and Campbell, M. (2020). Blood-brain barrier regulation in psychiatric disorders. Neurosci. Lett. 726:133664. doi: 10.1016/j.neulet.2018.06. 033

Keep, R. F., and Jones, H. C. (1990). Cortical microvessels during brain development: a morphometric study in the rat. Microvasc. Res. 40, 412-426. doi: 10.1016/0026-2862(90)90036-q

Kiernan, E. A., Wang, T., Vanderplow, A. M., Cherukuri, S., Cahill, M. E., and Watters, J. J. (2019). Neonatal intermittent hypoxia induces lasting sex-specific augmentation of rat microglial cytokine expression. Front. Immunol. 10:1479. doi: $10.3389 /$ fimmu.2019.01479

Kim, S.-G., and Ogawa, S. (2012). Biophysical and physiological origins of blood oxygenation level-dependent fMRI signals. J. Cereb. Blood Flow Metab. Off. J. Int. Soc. Cereb. Blood Flow Metab. 32, 1188-1206. doi: 10.1038/jcbfm.2012.23

Kindler, J., Jann, K., Homan, P., Hauf, M., Walther, S., Strik, W., et al. (2015). Static and dynamic characteristics of cerebral blood flow during the resting state in schizophrenia. Schizophr. Bull. 41, 163-170. doi: 10.1093/schbul/sbt180
Kinou, M., Takizawa, R., Marumo, K., Kawasaki, S., Kawakubo, Y., Fukuda, M., et al. (2013). Differential spatiotemporal characteristics of the prefrontal hemodynamic response and their association with functional impairment in schizophrenia and major depression. Schizophr. Res. 150, 459-467. doi: 10.1016/ j.schres.2013.08.026

Kircher, T. T. J., Rapp, A., Grodd, W., Buchkremer, G., Weiskopf, N., Lutzenberger, W., et al. (2004). Mismatch negativity responses in schizophrenia: a combined fMRI and whole-head MEG study. Am. J. Psychiatry 161, 294-304. doi: 10.1176/ appi.ajp.161.2.294

Kisler, K., Nelson, A. R., Montagne, A., and Zlokovic, B. V. (2017). Cerebral blood flow regulation and neurovascular dysfunction in Alzheimer disease. Nat. Rev. Neurosci. 18, 419-434. doi: 10.1038/nrn.2017.48

Kleinberger, G., Brendel, M., Mracsko, E., Wefers, B., Groeneweg, L., Xiang, X., et al. (2017). The FTD-like syndrome causing TREM2 T66M mutation impairs microglia function, brain perfusion, and glucose metabolism. EMBO J. 36, 1837-1853. doi: 10.15252/embj.201796516

Korpela, H., Miettunen, J., Rautio, N., Isohanni, M., Järvelin, M.-R., Jääskeläinen, E., et al. (2020). Early environmental factors and somatic comorbidity in schizophrenia and nonschizophrenic psychoses: a 50-year follow-up of the Northern Finland Birth Cohort 1966. Eur. Psychiatry J. Assoc. Eur. Psychiatr. 63:e24. doi: 10.1192/j.eurpsy.2020.25

Korte, N., Nortley, R., and Attwell, D. (2020). Cerebral blood flow decrease as an early pathological mechanism in Alzheimer's disease. Acta Neuropathol. (Berl.) 140, 793-810. doi: 10.1007/s00401-020-02215-w

Kozberg, M. G., Chen, B. R., DeLeo, S. E., Bouchard, M. B., and Hillman, E. M. C. (2013). Resolving the transition from negative to positive blood oxygen leveldependent responses in the developing brain. Proc. Natl. Acad. Sci. U.S.A. 110, 4380-4385. doi: 10.1073/pnas.1212785110

Kozberg, M., and Hillman, E. (2016). Neurovascular coupling and energy metabolism in the developing brain. Prog. Brain Res. 225, 213-242. doi: 10.1016/ bs.pbr.2016.02.002

Kusaka, T., Kawada, K., Okubo, K., Nagano, K., Namba, M., Okada, H., et al. (2004). Noninvasive optical imaging in the visual cortex in young infants. Hum. Brain Mapp. 22, 122-132. doi: 10.1002/hbm.20020

Lacoste, B., Comin, C. H., Ben-Zvi, A., Kaeser, P. S., Xu, X., Costa, L., et al. (2014). Sensory-related neural activity regulates the structure of vascular networks in the cerebral cortex. Neuron 83, 1117-1130. doi: 10.1016/j.neuron.2014.07.034

Lefebvre, S., Very, E., Jardri, R., Horn, M., Yrondi, A., Delmaire, C., et al. (2020). The neural correlates of the visual consciousness in schizophrenia: an fMRI study. Eur. Arch. Psychiatry Clin. Neurosci. doi: 10.1007/s00406-020-01167-2 [Epub ahead of print].

Letourneur, A., Chen, V., Waterman, G., and Drew, P. J. (2014). A method for longitudinal, transcranial imaging of blood flow and remodeling of the cerebral vasculature in postnatal mice. Physiol. Rep. 2:e12238. doi: 10.14814/phy2.12238

Liao, S. M., Gregg, N. M., White, B. R., Zeff, B. W., Bjerkaas, K. A., Inder, T. E., et al. (2010). Neonatal hemodynamic response to visual cortex activity: high-density near-infrared spectroscopy study. J. Biomed. Opt. 15:026010. doi: $10.1117 / 1.3369809$

Lindblom, P., Gerhardt, H., Liebner, S., Abramsson, A., Enge, M., Hellstrom, M., et al. (2003). Endothelial PDGF-B retention is required for proper investment of pericytes in the microvessel wall. Genes Dev. 17, 1835-1840. doi: 10.1101/gad. 266803

Longden, T. A., Dabertrand, F., Koide, M., Gonzales, A. L., Tykocki, N. R., Brayden, J. E., et al. (2017). Capillary K+-sensing initiates retrograde hyperpolarization to increase local cerebral blood flow. Nat. Neurosci. 20, 717-726. doi: 10.1038/nn. 4533

Lucitti, J. L., Jones, E. A. V., Huang, C., Chen, J., Fraser, S. E., and Dickinson, M. E. (2007). Vascular remodeling of the mouse yolk sac requires hemodynamic force. Dev. Camb. Engl. 134, 3317-3326. doi: 10.1242/dev.02883

Maes, M., Sirivichayakul, S., Kanchanatawan, B., and Vodjani, A. (2019). Breakdown of the paracellular tight and adherens junctions in the gut and blood brain barrier and damage to the vascular barrier in patients with deficit schizophrenia. Neurotox. Res. 36, 306-322. doi: 10.1007/s12640-019-00054-6

Malaspina, D., Harkavy-Friedman, J., Corcoran, C., Mujica-Parodi, L., Printz, D., Gorman, J. M., et al. (2004). Resting neural activity distinguishes subgroups of schizophrenia patients. Biol. Psychiatry 56, 931-937. doi: 10.1016/j.biopsych. 2004.09.013 
Marshall, C. R., Howrigan, D. P., Merico, D., Thiruvahindrapuram, B., Wu, W., Greer, D. S., et al. (2017). Contribution of copy number variants to schizophrenia from a genome-wide study of 41,321 subjects. Nat. Genet. 49, 27-35. doi: 10.1038/ng.3725

Mathiisen, T. M., Lehre, K. P., Danbolt, N. C., and Ottersen, O. P. (2010). The perivascular astroglial sheath provides a complete covering of the brain microvessels: an electron microscopic 3D reconstruction. Glia 58, 1094-1103. doi: 10.1002/glia.20990

Mayer, A. R., Hanlon, F. M., Dodd, A. B., Yeo, R. A., Haaland, K. Y., Ling, J. M., et al. (2016). Proactive response inhibition abnormalities in the sensorimotor cortex of patients with schizophrenia. J. Psychiatry Neurosci. JPN 41, 312-321. doi: 10.1503/jpn.150097

Mayer, A. R., Ruhl, D., Merideth, F., Ling, J., Hanlon, F. M., Bustillo, J., et al. (2013). Functional imaging of the hemodynamic sensory gating response in schizophrenia. Hum. Brain Mapp. 34, 2302-2312. doi: 10.1002/hbm.22065

McConnell, H. L., Kersch, C. N., Woltjer, R. L., and Neuwelt, E. A. (2017). The translational significance of the neurovascular unit. J. Biol. Chem. 292, 762-770. doi: $10.1074 /$ jbc.R116.760215

McGlashan, T. H. (2011). Eugen Bleuler: centennial anniversary of his 1911 publication of Dementia Praecox or the group of schizophrenias. Schizophr Bull. 37, 1101-1103. doi: 10.1093/schbul/sbr130

Meier, M. H., Shalev, I., Moffitt, T. E., Kapur, S., Keefe, R. S. E., Wong, T., et al. (2013). Microvascular abnormality in schizophrenia as shown by retinal imaging. Am. J. Psychiatry 170, 1451-1459. doi: 10.1176/appi.ajp.2013. 13020234

Melkersson, K., and Bensing, S. (2018). Signs of impaired blood-brain barrier function and lower IgG synthesis within the central nervous system in patients with schizophrenia or related psychosis, compared to that in controls. Neuro Endocrinol. Lett. 39, 33-42.

Menard, C., Pfau, M. L., Hodes, G. E., Kana, V., Wang, V. X., Bouchard, S., et al. (2017). Social stress induces neurovascular pathology promoting depression. Nat. Neurosci. 20, 1752-1760. doi: 10.1038/s41593-017-0010-3

Mishra, A., Reynolds, J. P., Chen, Y., Gourine, A. V., Rusakov, D. A., and Attwell, D. (2016). Astrocytes mediate neurovascular signaling to capillary pericytes but not to arterioles. Nat. Neurosci. 19, 1619-1627. doi: 10.1038/nn.4428

Mulligan, S. J., and MacVicar, B. A. (2004). Calcium transients in astrocyte endfeet cause cerebrovascular constrictions. Nature 431, 195-199. doi: 10.1038/ nature 02827

Mwansisya, T. E., Hu, A., Li, Y., Chen, X., Wu, G., Huang, X., et al. (2017). Task and resting-state fMRI studies in first-episode schizophrenia: a systematic review. Schizophr. Res. 189, 9-18. doi: 10.1016/j.schres.2017.02.026

Najjar, S., Pahlajani, S., De Sanctis, V., Stern, J. N. H., Najjar, A., and Chong, D. (2017). Neurovascular unit dysfunction and blood-brain barrier hyperpermeability contribute to schizophrenia neurobiology: a theoretical integration of clinical and experimental evidence. Front. Psychiatry 8:83. doi: 10.3389/fpsyt.2017.00083

Nation, D. A., Sweeney, M. D., Montagne, A., Sagare, A. P., D’Orazio, L. M., Pachicano, M., et al. (2019). Blood-brain barrier breakdown is an early biomarker of human cognitive dysfunction. Nat. Med. 25, 270-276. doi: 10. 1038/s41591-018-0297-y

Nelson, A. R., Sweeney, M. D., Sagare, A. P., and Zlokovic, B. V. (2016). Neurovascular dysfunction and neurodegeneration in dementia and Alzheimer's disease. Biochim. Biophys. Acta 1862, 887-900. doi: 10.1016/j.bbadis.2015.12.016

Noda, T., Nakagome, K., Setoyama, S., and Matsushima, E. (2017). Working memory and prefrontal/temporal hemodynamic responses during posttask period in patients with schizophrenia: a multi-channel near-infrared spectroscopy study. J. Psychiatr. Res. 95, 288-298. doi: 10.1016/j.jpsychires.2017. 09.001

Norman, M. G., and O'Kusky, J. R. (1986). The growth and development of microvasculature in human cerebral cortex. J. Neuropathol. Exp. Neurol. 45, 222-232. doi: 10.1097/00005072-198605000-00004

Norris, E. H., and Strickland, S. (2017). Fibrinogen in the nervous system: glia beware. Neuron 96, 951-953. doi: 10.1016/j.neuron.2017.11.021

Ogawa, S., Tank, D. W., Menon, R., Ellermann, J. M., Kim, S. G., Merkle, H., et al. (1992). Intrinsic signal changes accompanying sensory stimulation: functional brain mapping with magnetic resonance imaging. Proc. Natl. Acad. Sci. U.S.A. 89, 5951-5955. doi: 10.1073/pnas.89.13.5951
Omidinia, E., Mashayekhi Mazar, F., Shahamati, P., Kianmehr, A., and Shahbaz Mohammadi, H. (2014). Polymorphism of the CLDN5 gene and Schizophrenia in an Iranian Population. Iran. J. Public Health 43, 79-83.

Ouellette, J., Toussay, X., Comin, C. H., Costa, L., da, F., Ho, M., et al. (2020). Vascular contributions to $16 \mathrm{p} 11.2$ deletion autism syndrome modeled in mice. Nat. Neurosci. 23, 1090-1101. doi: 10.1038/s41593-020-0663-1

Paolicelli, R. C., Bolasco, G., Pagani, F., Maggi, L., Scianni, M., Panzanelli, P., et al. (2011). Synaptic pruning by microglia is necessary for normal brain development. Science 333, 1456-1458. doi: 10.1126/science.1202529

Paredes, I., Himmels, P., and Ruiz de Almodóvar, C. (2018). Neurovascular communication during CNS development. Dev. Cell 45, 10-32. doi: 10.1016/ j.devcel.2018.01.023

Pearson-Leary, J., Eacret, D., Chen, R., Takano, H., Nicholas, B., and Bhatnagar, S. (2017). Inflammation and vascular remodeling in the ventral hippocampus contributes to vulnerability to stress. Transl. Psychiatry 7:e1160. doi: 10.1038/ tp.2017.122

Peterson, E. C., Wang, Z., and Britz, G. (2011). Regulation of cerebral blood flow. Int. J. Vasc. Med. 2011:823525. doi: 10.1155/2011/823525

Pinkham, A., Loughead, J., Ruparel, K., Wu, W.-C., Overton, E., Gur, R., et al. (2011). Resting quantitative cerebral blood flow in schizophrenia measured by pulsed arterial spin labeling perfusion MRI. Psychiatry Res. 194, 64-72. doi: 10.1016/j.pscychresns.2011.06.013

$\mathrm{Pu}$, S., Nakagome, K., Itakura, M., Iwata, M., Nagata, I., and Kaneko, K. (2016). The association between cognitive deficits and prefrontal hemodynamic responses during performance of working memory task in patients with schizophrenia. Schizophr. Res. 172, 114-122. doi: 10.1016/j.schres.2016. 01.045

Pu, S., Nakagome, K., Itakura, M., Yamanashi, T., Sugie, T., Miura, A., et al. (2015). Self-reported social functioning and prefrontal hemodynamic responses during a cognitive task in schizophrenia. Psychiatry Res. 234, 121-129. doi: 10.1016/j. pscychresns.2015.09.008

Pulver, A. E. (2000). Search for schizophrenia susceptibility genes. Biol. Psychiatry 47, 221-230. doi: 10.1016/s0006-3223(99)00281-4

Qiu, H., Zhu, X., Wang, L., Pan, J., Pu, X., Zeng, X., et al. (2019). Attributable risk of hospital admissions for overall and specific mental disorders due to particulate matter pollution: a time-series study in Chengdu. China. Environ. Res. 170, 230-237. doi: 10.1016/j.envres.2018.12.019

Raabe, F. J., Galinski, S., Papiol, S., Falkai, P. G., Schmitt, A., and Rossner, M. J. (2018). Studying and modulating schizophrenia-associated dysfunctions of oligodendrocytes with patient-specific cell systems. NPJ Schizophr. 4:23. doi: 10.1038/s41537-018-0066-4

Raja, R., Rosenberg, G. A., and Caprihan, A. (2018). MRI measurements of blood-brain barrier function in dementia: a review of recent studies. Neuropharmacology 134, 259-271. doi: 10.1016/j.neuropharm.2017. 10.034

Risser, L., Plouraboué, F., Cloetens, P., and Fonta, C. (2009). A 3D-investigation shows that angiogenesis in primate cerebral cortex mainly occurs at capillary level. Int. J. Dev. Neurosci. Off. J. Int. Soc. Dev. Neurosci. 27, 185-196. doi: 10.1016/j.ijdevneu.2008.10.006

Ritsner, M., Ben-Avi, I., Ponizovsky, A., Timinsky, I., Bistrov, E., and Modai, I. (2003). Quality of life and coping with schizophrenia symptoms. Qual. Life Res. Int. J. Qual. Life Asp. Treat. Care Rehabil. 12, 1-9. doi: 10.1023/a: 1022049111822

Rogdaki, M., Gudbrandsen, M., McCutcheon, R. A., Blackmore, C. E., Brugger, S., Ecker, C., et al. (2020). Magnitude and heterogeneity of brain structural abnormalities in 22q11.2 deletion syndrome: a meta-analysis. Mol. Psychiatry 25, 1704-1717. doi: 10.1038/s41380-019-0638-3

Rowan, R. A., and Maxwell, D. S. (1981). Patterns of vascular sprouting in the postnatal development of the cerebral cortex of the rat. Am. J. Anat. 160, 247-255. doi: 10.1002/aja.1001600303

Sakatani, K., Chen, S., Lichty, W., Zuo, H., and Wang, Y. P. (1999). Cerebral blood oxygenation changes induced by auditory stimulation in newborn infants measured by near infrared spectroscopy. Early Hum. Dev. 55, 229-236. doi: 10.1016/s0378-3782(99)00019-5

Schafer, D. P., Lehrman, E. K., Kautzman, A. G., Koyama, R., Mardinly, A. R., Yamasaki, R., et al. (2012). Microglia sculpt postnatal neural circuits in an activity and complement-dependent manner. Neuron 74, 691-705. doi: 10. 1016/j.neuron.2012.03.026 
Scheef, L., Manka, C., Daamen, M., Kühn, K.-U., Maier, W., Schild, H. H., et al. (2010). Resting-state perfusion in nonmedicated schizophrenic patients: a continuous arterial spin-labeling 3.0-T MR study. Radiology 256, 253-260. doi: 10.1148/radiol.10091224

Schmidt-Kastner, R., van Os, J., Esquivel, G., Steinbusch, H. W. M., and Rutten, B. P. F. (2012). An environmental analysis of genes associated with schizophrenia: hypoxia and vascular factors as interacting elements in the neurodevelopmental model. Mol. Psychiatry 17, 1194-1205. doi: 10.1038/mp. 2011.183

Segarra, M., Aburto, M. R., Cop, F., Llaó-Cid, C., Härtl, R., Damm, M., et al. (2018). Endothelial Dab1 signaling orchestrates neuro-glia-vessel communication in the central nervous system. Science 361:eaao2861. doi: 10.1126/science.aao 2861

Sekar, A., Bialas, A. R., de Rivera, H., Davis, A., Hammond, T. R., Kamitaki, N., et al. (2016). Schizophrenia risk from complex variation of complement component 4. Nature 530, 177-183. doi: 10.1038/nature16549

Sellgren, C. M., Gracias, J., Watmuff, B., Biag, J. D., Thanos, J. M., Whittredge, P. B., et al. (2019). Increased synapse elimination by microglia in schizophrenia patient-derived models of synaptic pruning. Nat. Neurosci. 22, 374-385. doi: 10.1038/s41593-018-0334-7

Sengupta, P. (2013). The laboratory rat: relating its age with human's. Int. J. Prev. Med. 4, 624-630.

Senitz, D., and Winkelmann, E. (1991). [Neuronal structure abnormality in the orbito-frontal cortex of schizophrenics]. J. Hirnforsch. 32, 149-158.

Sie, L. T. L., Rombouts, S. A., Valk, I. J., Hart, A. A., Scheltens, P., and van der Knaap, M. S. (2001). Functional MRI of visual cortex in sedated 18 month-old infants with or without periventricular leukomalacia. Dev. Med. Child Neurol. 43, 486-490. doi: 10.1017/s0012162201000895

Sintsov, M., Suchkov, D., Khazipov, R., and Minlebaev, M. (2017). Developmental changes in sensory-evoked optical intrinsic signals in the rat barrel cortex. Front. Cell. Neurosci. 11:392. doi: 10.3389/fncel.2017.00392

Soltanlou, M., Sitnikova, M. A., Nuerk, H.-C., and Dresler, T. (2018). Applications of functional near-infrared spectroscopy (fNIRS) in studying cognitive development: the case of mathematics and language. Front. Psychol. 9:277. doi: 10.3389/fpsyg.2018.00277

St-Pierre, M.-K., Šimončičová, E., Bögi, E., and Tremblay, M. -È (2020). Shedding light on the dark side of the microglia. ASN Neuro 12:1759091420925335. doi: 10.1177/1759091420925335

Strawbridge, R. J., Ward, J., Cullen, B., Tunbridge, E. M., Hartz, S., Bierut, L., et al. (2018). Genome-wide analysis of self-reported risk-taking behaviour and crossdisorder genetic correlations in the UK Biobank cohort. Transl. Psychiatry 8:39. doi: 10.1038/s41398-017-0079-1

Sweeney, M. D., Zhao, Z., Montagne, A., Nelson, A. R., and Zlokovic, B. V. (2019). Blood-brain barrier: from physiology to disease and back. Physiol. Rev. 99, 21-78. doi: 10.1152/physrev.00050.2017

Sweeting, J., Duflou, J., and Semsarian, C. (2013). Postmortem analysis of cardiovascular deaths in schizophrenia: a 10-year review. Schizophr. Res. 150, 398-403. doi: 10.1016/j.schres.2013.08.029

Taga, G., Asakawa, K., Maki, A., Konishi, Y., and Koizumi, H. (2003). Brain imaging in awake infants by near-infrared optical topography. Proc. Natl. Acad. Sci. U.S.A. 100, 10722-10727. doi: 10.1073/pnas.1932552100

Takizawa, R., Hashimoto, K., Tochigi, M., Kawakubo, Y., Marumo, K., Sasaki, T., et al. (2009). Association between sigma-1 receptor gene polymorphism and prefrontal hemodynamic response induced by cognitive activation in schizophrenia. Prog. Neuropsychopharmacol. Biol. Psychiatry 33, 491-498. doi: 10.1016/j.pnpbp.2009.01.014

Tang, S. X., Yi, J. J., Calkins, M. E., Whinna, D. A., Kohler, C. G., Souders, M. C., et al. (2014). Psychiatric disorders in 22q11.2 deletion syndrome are prevalent but undertreated. Psychol. Med. 44, 1267-1277. doi: 10.1017/ S0033291713001669

Tata, M., Ruhrberg, C., and Fantin, A. (2015). Vascularisation of the central nervous system. Mech. Dev. 138(Pt 1), 26-36. doi: 10.1016/j.mod.2015.07.001

Thompson, C. A., Karelis, J., Middleton, F. A., Gentile, K., Coman, I. L., Radoeva, P. D., et al. (2017). Associations between neurodevelopmental genes, neuroanatomy, and ultra high risk symptoms of psychosis in 22q11.2 deletion syndrome. Am. J. Med. Genet. Part B Neuropsychiatr. Genet. Off. Publ. Int. Soc. Psychiatr. Genet. 174, 295-314. doi: 10.1002/ajmg.b.32515

Tregellas, J. R., Ellis, J., Shatti, S., Du, Y. P., and Rojas, D. C. (2009). Increased hippocampal, thalamic, and prefrontal hemodynamic response to an urban noise stimulus in schizophrenia. Am. J. Psychiatry 166, 354-360. doi: 10.1176/ appi.ajp.2008.08030411

Tregellas, J. R., Tanabe, J. L., Miller, D. E., Ross, R. G., Olincy, A., and Freedman, R. (2004). Neurobiology of smooth pursuit eye movement deficits in schizophrenia: an fMRI study. Am. J. Psychiatry 161, 315-321. doi: 10.1176/ appi.ajp.161.2.315

Uhlirova, H., Kılı ç, K., Tian, P., Thunemann, M., Desjardins, M., Saisan, P. A., et al. (2016). Cell type specificity of neurovascular coupling in cerebral cortex. eLife 5:e14315. doi: 10.7554/eLife.14315

Uranova, N., Zimina, I., Vikhreva, O., Rachmanova, V., Klintsova, A., and Orlovskaya, D. (2013). Reduced capillary density in the prefrontal cortex in schizophrenia. Am. J. Med. Sci. Med. 1, 45-51. doi: 10.12691/ajmsm-1-3-3

Uranova, N. A., Zimina, I. S., Vikhreva, O. V., Krukov, N. O., Rachmanova, V. I., and Orlovskaya, D. D. (2010). Ultrastructural damage of capillaries in the neocortex in schizophrenia. World J. Biol. Psychiatry Off. J. World Fed. Soc. Biol. Psychiatry 11, 567-578. doi: 10.3109/15622970903414188

Vanlandewijck, M., He, L., Mäe, M. A., Andrae, J., Ando, K., Del Gaudio, F., et al. (2018). A molecular atlas of cell types and zonation in the brain vasculature. Nature 554, 475-480. doi: 10.1038/nature25739

Vannucci, R. C., and Vannucci, S. J. (2000). Glucose metabolism in the developing brain. Semin. Perinatol. 24, 107-115. doi: 10.1053/sp.2000.6361

Villabona-Rueda, A., Erice, C., Pardo, C. A., and Stins, M. F. (2019). The evolving concept of the blood brain barrier (BBB): from a single static barrier to a heterogeneous and dynamic relay center. Front. Cell. Neurosci. 13:405. doi: 10.3389/fncel.2019.00405

Wang, D. B., Blocher, N. C., Spence, M. E., Rovainen, C. M., and Woolsey, T. A. (1992). Development and remodeling of cerebral blood vessels and their flow in postnatal mice observed with in vivo videomicroscopy. J. Cereb. Blood Flow Metab. Off. J. Int. Soc. Cereb. Blood Flow Metab. 12, 935-946. doi: 10.1038/jcbfm. 1992.130

Watanabe, H., Homae, F., Nakano, T., and Taga, G. (2008). Functional activation in diverse regions of the developing brain of human infants. NeuroImage 43, 346-357. doi: 10.1016/j.neuroimage.2008.07.014

Weber, B., Keller, A. L., Reichold, J., and Logothetis, N. K. (2008). The microvascular system of the striate and extrastriate visual cortex of the macaque. Cereb. Cortex N. Y. N 1991, 2318-2330. doi: 10.1093/cercor/bhm259

Webster, M. J., Knable, M. B., Johnston-Wilson, N., Nagata, K., Inagaki, M., and Yolken, R. H. (2001). Immunohistochemical localization of phosphorylated glial fibrillary acidic protein in the prefrontal cortex and hippocampus from patients with schizophrenia, bipolar disorder, and depression. Brain. Behav. Immun. 15, 388-400. doi: 10.1006/brbi.2001.0646

Weinstein, J. J., Chohan, M. O., Slifstein, M., Kegeles, L. S., Moore, H., and Abi-Dargham, A. (2017). Pathway-specific dopamine abnormalities in schizophrenia. Biol. Psychiatry 81, 31-42. doi: 10.1016/j.biopsych.2016.03. 2104

Whiteman, A. C., Santosa, H., Chen, D. F., Perlman, S., and Huppert, T. (2018). Investigation of the sensitivity of functional near-infrared spectroscopy brain imaging to anatomical variations in 5- to 11-year-old children. Neurophotonics 5:011009. doi: 10.1117/1.NPh.5.1.011009

Whiteus, C., Freitas, C., and Grutzendler, J. (2014). Perturbed neural activity disrupts cerebral angiogenesis during a postnatal critical period. Nature 505, 407-411. doi: 10.1038/nature12821

Yamada, H., Sadato, N., Konishi, Y., Muramoto, S., Kimura, K., Tanaka, M., et al. (2000). A milestone for normal development of the infantile brain detected by functional MRI. Neurology 55, 218-223. doi: 10.1212/wnl.55.2.218

Yang, M., Yang, Z., Yuan, T., Feng, W., and Wang, P. (2019). A systemic review of functional near-infrared spectroscopy for stroke: current application and future directions. Front. Neurol. 10:58. doi: 10.3389/fneur.2019. 00058

Zaramella, P., Freato, F., Amigoni, A., Salvadori, S., Marangoni, P., Suppiej, A., et al. (2001). Brain auditory activation measured by near-infrared spectroscopy 
(NIRS) in neonates. Pediatr. Res. 49, 213-219. doi: 10.1203/00006450200102000-00014

Zeller, K., Vogel, J., and Kuschinsky, W. (1996). Postnatal distribution of Glut1 glucose transporter and relative capillary density in blood-brain barrier structures and circumventricular organs during development. Brain Res. Dev. Brain Res. 91, 200-208. doi: 10.1016/0165-3806(95) 00177-8

Zhu, J., Zhuo, C., Xu, L., Liu, F., Qin, W., and Yu, C. (2017). Altered coupling between resting-state cerebral blood flow and functional connectivity in schizophrenia. Schizophr. Bull. 43, 1363-1374. doi: 10.1093/schbul/ sbx051
Conflict of Interest: The authors declare that the research was conducted in the absence of any commercial or financial relationships that could be construed as a potential conflict of interest.

Copyright $\odot 2021$ Carrier, Guilbert, Lévesque, Tremblay and Desjardins. This is an open-access article distributed under the terms of the Creative Commons Attribution License (CC BY). The use, distribution or reproduction in other forums is permitted, provided the original author(s) and the copyright owner(s) are credited and that the original publication in this journal is cited, in accordance with accepted academic practice. No use, distribution or reproduction is permitted which does not comply with these terms. 